\title{
Voluntary and therapeutic causes of water intoxication and hypertonic dehydration: perinatal risks in mother and offspring
}

\author{
Rolf Zetterström
}

Acta Pædiatrica, Karolinska Hospital, Stockholm, Sweden

\section{Abstract}

Owing to the attitude that a high intake of fluid enhances beauty, young women may drink far more water than they need. This behaviour may have serious consequences for the mother and her offspring during delivery because of a risk of severe hyponatraemia. In contrast, hypernatraemic dehydration in the newborn infant may be considered when exclusively breast-fed infants postnatally lose $10 \%$ or more of their birth weight. This previously rather neglected condition should particularly be taken into account in preterm infants.

\section{Introduction}

Human fluid and electrolyte balance is regulated by an intricate and complex mechanism by which extracellular and intracellular volumes, as well as electrolyte concentrations, are kept at constant levels during various conditions. However, when the challenge is too severe for the regulatory homoeostatic forces, such as aldosterone, antidiuretic hormone or aquaporins, the balance breaks down and a monotonic, hypotonic or hypertonic overhydration or dehydration develops.

As the regulatory mechanism controlling intracellular volume, and particularly that of the brain cells, is very efficient, mild normotonic dehydration as seen after moderate sweating or in connection with slight gastroenteritis is relatively well tolerated. However, when the plasma volume declines to such an extent that the nutritional blood flow to vital organs is reduced to a certain extent, symptoms appear. In hypotonic or hypertonic dehydration or overhydration, the volume changes and the abnormal tonicity of extracellular fluid causes functional disturbances of vital organs such as the brain, heart and kidneys. In a state of hypotonicity from loss of sodium in excess of water or from overload of fluid, the content of water in the brain cells will increase, resulting in oedema of the brain (1). In hypertonicity when sodium is retained in excess of water, the brain cells lose water to obtain intracellular and extracellular oncotic equilibrium. As a result of this mechanism the brain cells shrink and the small blood vessels may rupture.

\section{General aspects on homoeostatic dysfunction}

To obtain accurate information about fluid and electrolyte balance, intake and losses have to be estimated. The mechanisms that regulate sodium and water balance may be underdeveloped, as in newborn infants and particularly in those who are preterm (2).

The regulating functions are disturbed in nephrogenic diabetes insipidus (3), deficient secretions of antidiuretic hormone (4) and a number of other conditions. Low sodium levels occur frequently in acute febrile diseases owing to losses of water by sweating (5) and have particularly been observed in febrile seizures in which not only fever but also hypothalamic dysregulation may play a role (6).

Water intoxication is a well-known complication when the stomach is pumped or when enemas are given without the addition of extra salt to the fluid. However, water intoxication may also result when the fluid intake is high, as in psychogenic polydipsia, during treatment with a drug such as desmopressin to prevent bed wetting or in von Willebrand's disease (7). 


\section{Voluntary water intoxication}

Excessive voluntary intake of fluid has been reported to cause water intoxication with hyponatraemia and elevated intracranial pressure in healthy women (8). This complication is not always realized by all "health experts", who have propagandized the effects of a high fluid intake in enhancing beauty and vitality, a message that appeals to many adolescents and young women. The concept behind this idea is that large amounts of fluid clean the body by washing out toxic substances, which otherwise damage the beauty, reduce the sparkle of the eyes and adversely affect physical fitness. Many women today carry bottles of water or some soda preparation from which they repeatedly drink fluid. In this way, they may consume up to $500 \mathrm{ml}$ within $1 \mathrm{~h}$. Most remarkable is that this habit is supported by many midwives giving advice to pregnant women and also by nurses working at child health centres. These nurses do not realize that breast-feeding in itself promotes a powerful thirst stimulus in the lactating mother and that she increases her fluid intake $12-16 \%$ by a self-regulatory mechanism (9). Although moderate dehydration does not affect milk production, lactating women in dry and hot climates may use physiological and behavioural means to meet their fluid requirements. Thus, extra fluid may be of value for lactating women who are travelling in hot countries, who lose large volumes of fluid.

Recently, it has been reported that excessive fluid intake immediately before and during pregnancy may cause water intoxication with severe symptoms of acute brain dysfunction in both the mother and her offspring (10). A report is given of a case of a mother who was used to having the same high fluid intake as many of her friends, and who continued to drink excessively when she went into labour. She suddenly became somnolent and developed seizures, and an emergency caesarean section had to be performed. Water intoxication was suspected and her serum sodium concentration was found to be as low as $115 \mathrm{mmol}^{-1}$. Her term male infant needed assisted ventilation during the first minutes after birth. The child was then irritable and had attacks of crying, was hypertonic and had repeated apnoea. His serum sodium level was extremely low (105-115 mmol $\left.1^{-1}\right)$. In the same report, three other newborn babies were described who suffered seizures within the first hours of birth and severe hyponatraemia with serum sodium levels between 118 and 121 mmol $1^{-1}$, and whose mothers were also in the habit of drinking large amounts of water. As a result of oxytocin being pulsatively released by the mothers when they were in labour, their ability to deal with their excessive water intake was disrupted, resulting in water intoxication. In the paper, it was pointed out that the mechanism behind the perinatal water intoxication is probably the vasopressin-like action of oxytocin $(11-13)$.

As not only the mothers but also their offspring developed symptoms of water intoxication during delivery, the disturbance in the mother may also cause profound homoeostatic changes in the newborn infant. All four infants were found to have developed normally at between 3 and 10 months of age, but a longer follow-up study is needed to find whether they develop any sequelae. It should, however, be mentioned that hyponatraemia in preterm infants may be associated with leucomalacia (14). The fact that delivery may be faster and less complicated if the fluid intake during delivery is increased from 125 to $250 \mathrm{ml} \mathrm{h}^{-1}$ may be explained by changes in the release of oxytocin and vasopressin peptides (15), which may be unfavourable in the case of preterm deliveries (16).

\section{Early postnatal hypertonic dehydration and exclusive breast-feeding}

Recently, it has been found that infants who are exclusively breast-fed and whose fluid needs are not met may develop hypertonic dehydration during the neonatal period. This disturbance in fluid and electrolyte homoeostasis is probably due to a high sodium concentration in the milk in association with a relatively low-volume intake. The cases of two such infants were reported in a Turkish study (17). At a postnatal age of 5 and 7 days, they developed symptoms of hypertonic dehydration with serum sodium levels of 178 and $161 \mathrm{mmol}$ $1^{-1}$, respectively. Ten days after birth, the sodium concentration in the milk from the mothers was 50 and $45 \mathrm{mmol}^{-1}$, respectively, compared with a normal level of about $20 \mathrm{mmol}^{-1}$ (18). In both cases the pregnancy was unwanted. For this reason, it was concluded that disordered parenting styles and high sodium levels in breast milk are risk factors for unsuccessful lactogenesis. In this connection, it may also be mentioned that the author of the first textbook on paediatrics, Rosén von Rosenstein, in 1764 wrote that women in a bad mood 
should not breast-feed babies because their milk can be poisonous and thus dangerous for the child (19).

At the same time as the Turkish cases were reported, another paper was published describing hypernatraemia during the first week in exclusively breast-fed infants (20). Although no cause of hypernatraemia was found in these infants, it was pointed out that early hypernatraemic dehydration is a serious condition, which can be followed by permanent brain damage. The importance of recognizing this condition was stressed, and it should particularly be taken into account in centres where exclusive breast-feeding was a high priority. In Sweden, and other countries with a high prevalence of exclusive breast-feeding up to 3-4 months of age, the risk of early hypernatraemic dehydration should be kept in mind, particularly if the weight of newborn infants falls below $10 \%$ of the birth weight. Additional evidence for such a complication may be the development of fever in the baby and signs of bonding failure.

\section{References}

1. Vajda Z, Pedersen M, Dóczi T, et al. Effects of centrally administered arginine vasopressin and atrial natriuretic peptide on the development of brain edema in hyponatremic rats. Neurosurgery 2001; 49: 697-704.

2. Aperia A, Zetterström R. Renal control of fluid homeostasis in the newborn infant. Clin Perinatol 1982; 9: 523-33.

3. Bichet DG. Nephrogenic diabetes insipidus. Am J Med 1998; 105: 431-42.

4. Litwack G, Schmidt TJ. Biochemistry of hormones I: Polypeptide hormones. In: Devlin TM, ed. Textbook of biochemistry with clinical correlations, 4th edn. New York: Wiley-Liss; 1997. p. 839-91.

5. Gonzalez CF, Finberg L, Bluenstein DD. Electrolyte concentration during acute infections. Am J Dis Child 1964; 107: 476-82.

6. Kiviranta T, Airaksinen EM. Low sodium levels in serum are associated with subsequent febrile seizures. Acta Paediatr 1995; 84: 1372-4.

7. Norée E, Belfrage E, Zachrisson I, Enochsson E. Desmopressin gav vattenintoxikation. Läkartidningen 1994; 91: 515-6.
8. Kott E, Marcus Y. Acute brain edema due to water loading in a young man. Eur Neurol 1985; 24: 221-4.

9. Bentley GR. Hydration a limiting factor in lactation. Am J Hum Biol 1998; 10: 151-61.

10. Johansson S, Lindow S, Kapadia H, Norman M. Perinatal water intoxication due to excessive oral intake during labour. Acta Paediatr 2002; 91: 811-4.

11. Chou CL, DiGiovanni SR, Mejia R, et al. Oxytocin as an antidiuretic hormone. I. Concentration dependence of action. Am J Physiol 1995; 269: F70-7.

12. Joo KW, Jeon US, Kim JH, et al. The role of oxytocin in regulation of water balance in the kidney; its antidiuretic effect in a human body. Kidney Int 1999; 55: 1597.

13. Hoyle CHV. Neuropeptide families and their receptors: evolutionary perspectives. Brain Res 1999; 848: 1-25.

14. Kaplan SL, Feigin RD. Inappropriate secretion of antidiuretic hormone complicating neonatal hypoxicischemic encephalopathy. J Pediatr 1978; 92: 431-3.

15. Omar S, DeCristofaro JD, Agarwal BI, La Gramma EF. Effects of prenatal steroids on water and sodium homeostasis in extremely low birth weight neonates. Pediatrics 1999; 104: 482-8.

16. Garite TJ, Weeks J, Peters-Phair K, et al. A randomised controlled trial of the effect of increased intravenous hydration on the course of labor in nulliparous women. Am J Obstet Gynecol 2000; 183: 1544-8.

17. Kumral A, Duman N, Tatli MM, et al. Hypernatraemic dehydration due to high sodium concentrations in breast milk: possible relationship with unwanted pregnancy. Acta Paediatr 2002; 91: 1268-9.

18. Aperia A, Broberger O, Herin P, Zetterström R. Salt content in human breast milk during the three first weeks after delivery. Acta Paediatr 1979; 68: 441-2.

19. Rosén von Rosenstein. Underrättelser om Barnsjukdomar och deras botemedel. 1764. Cf. Zetterström R. Rosén von Rosenstein. His textbook and the award. Acta Paediatr 1995: 84: 965-70.

20. Laing IA, Wong CM. Hypernatraemia in the first few days: is the incidence rising? Arch Dis Child 2002; 87: $158-62$.

Rolf Zetterström

Acta Pædiatrica Building Z6: 04

Karolinska Hospital

SE-17I 76 Stockholm

Sweden

E-mail: rolf.zetterstrom@actapaediatrica.se 